\title{
Achieving MDGs 4 and 5 in Khyber Pakhtunkhwa: The role of family planning
}

Population Council

Follow this and additional works at: https://knowledgecommons.popcouncil.org/departments_sbsr-rh

Part of the Demography, Population, and Ecology Commons, Family, Life Course, and Society Commons, International Public Health Commons, Maternal and Child Health Commons, and the Women's Health Commons How does access to this work benefit you? Let us know!

\section{Recommended Citation}

"Achieving MDGs 4 and 5 in Khyber Pakhtunkhwa: The role of family planning," RAF Briefing Paper. Islamabad: Population Council, 2014. 


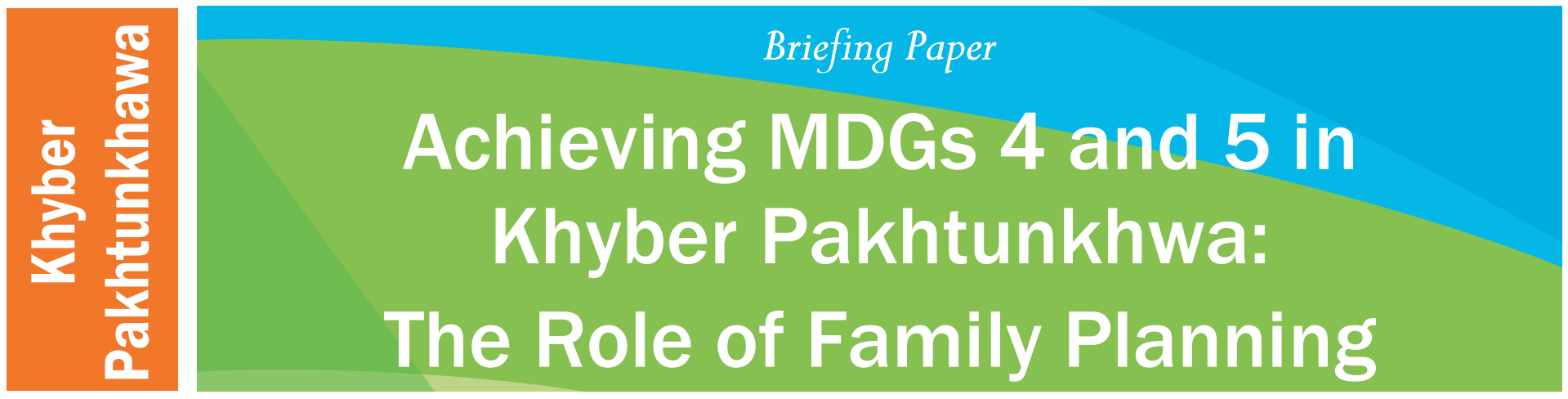

This briefing paper focuses on the policy options available to the KP government in affecting just how much KP's population will grow by 2050 and its potential to achieve MDGs 4 and 5.

\section{THE STATE OF MATERNAL HEALTH IN KP}

Maternal mortality is a leading cause of death among women of reproductive age in KP - about $27 \%$ of the deaths in this age group were pregnancy-related (PDHS 2006/07).

Approximately 1,700 women die each year in KP alone due to pregnancy-related factors despite the recent improvement in reproductive health indicators. Pregnancies that occur too early, too late, or too frequently increase the risk of maternal death. Lowering fertility rates by increasing the use of family planning can help reduce the number of pregnancy-related deaths.

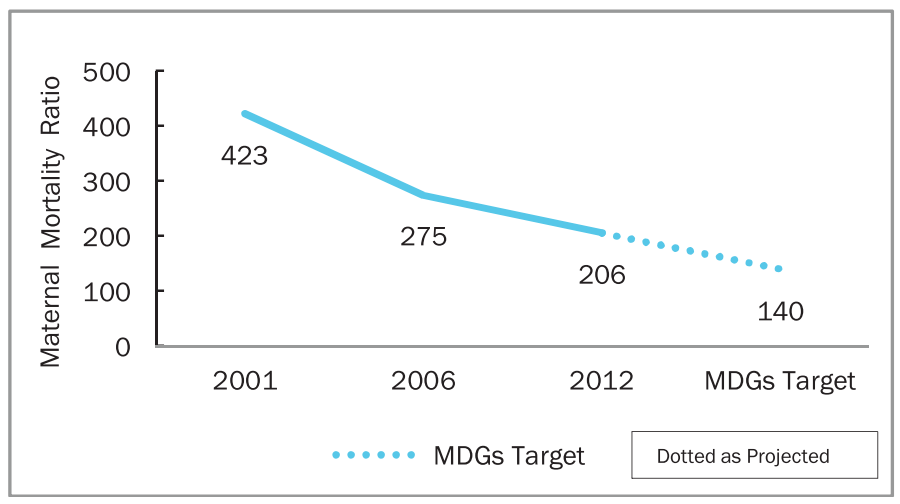

Figure 1: Trend in maternal mortality ratio and the MDG 5 target in $K P$

The good news is that there has been a decrease in maternal mortality in KP (Figure 1). The maternal mortality ratio (MMR) was estimated at 423 per 100,000 live births in 2001; in 2006, it was measured at 275 , and by 2012 it had fallen to 206 per 100,000 live births.

Maternal health indicators have improved over the last two decades and $61 \%$ of pregnant women in KP received antenatal care (ANC) in 2012 - a rise of 43 percentage points since 1991. The proportion of pregnant women assisted by a skilled birth attendant (SBA) during childbirth has also risen four times from $12 \%$ in 1991 to $48 \%$ in 2012 (Figure 2).

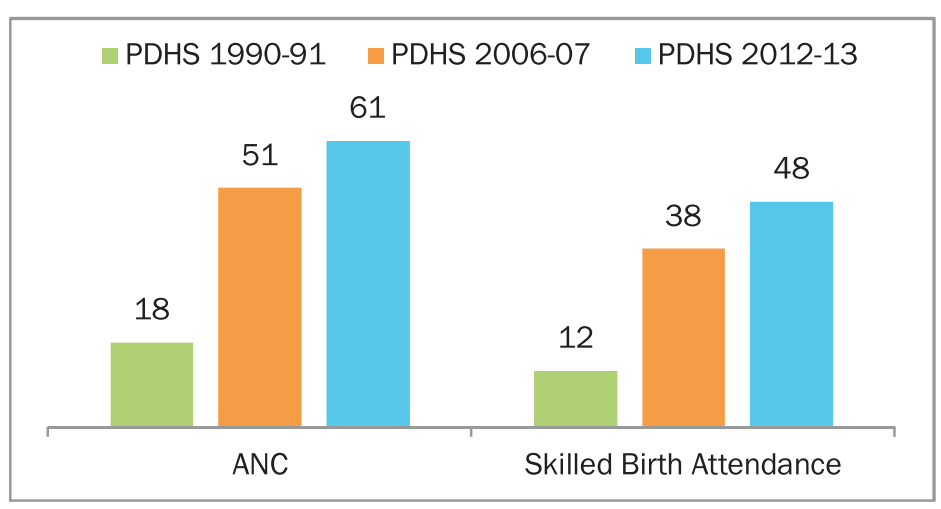

Figure 2: Maternal health indicators (in \%)

Urban-rural disparities in skilled birth attendance are highly significant in KP. The proportion of pregnant women assisted by SBAs in urban areas was 26 percentage points higher than in rural areas in 2012 (Figure 3). The proportion of deliveries assisted by SBAs also varies considerably by district, ranging from only $10 \%$ in Kohistan to the highest level (71\%) in Bannu (PSLMs 2010/11).

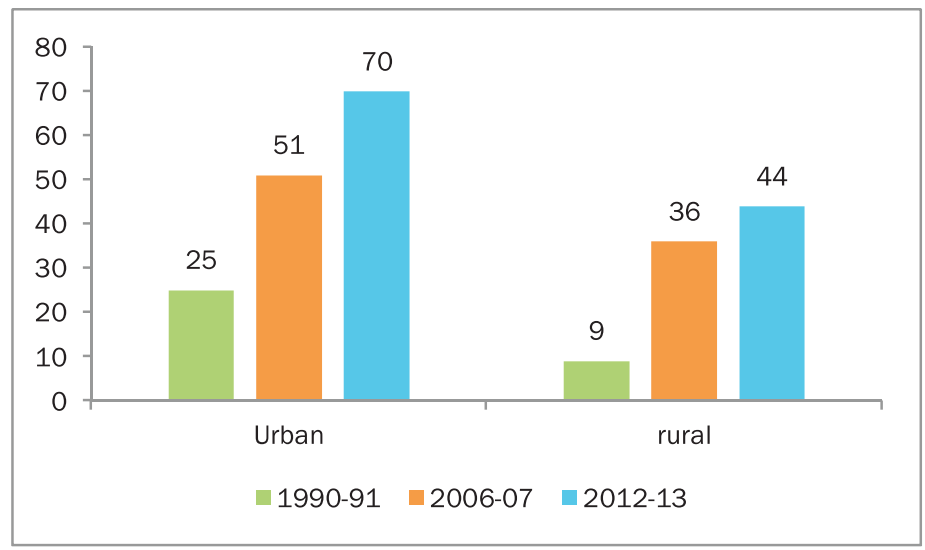

Figure 3: Skilled birth attendance by place of residence Source: PDHS

1,700 women in KP die annually due to pregnancy-related complications.

\section{POPULATION COUNCIL}

Ideas. Evidence. Impact

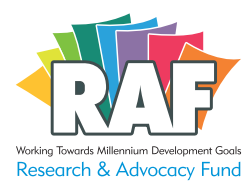




\section{THE MISSED OPPORTUNITY IN MATERNAL HEALTH: LOW CONTRACEPTIVE PREVALENCE IN KP}

The contraceptive prevalence rate (CPR) among married women in KP has risen from $25 \%$ in $2006 / 07$ to $28 \%$ by $2012 / 13$. This represents a 0.5 percentage-point annual rise over the last six years. (Figure 4). The use of modern methods has increased from $8 \%$ in 1991 to $20 \%$ in 2012 (Figure 4). A notable $8 \%$ of women of reproductive age reported using traditional methods in 2012.

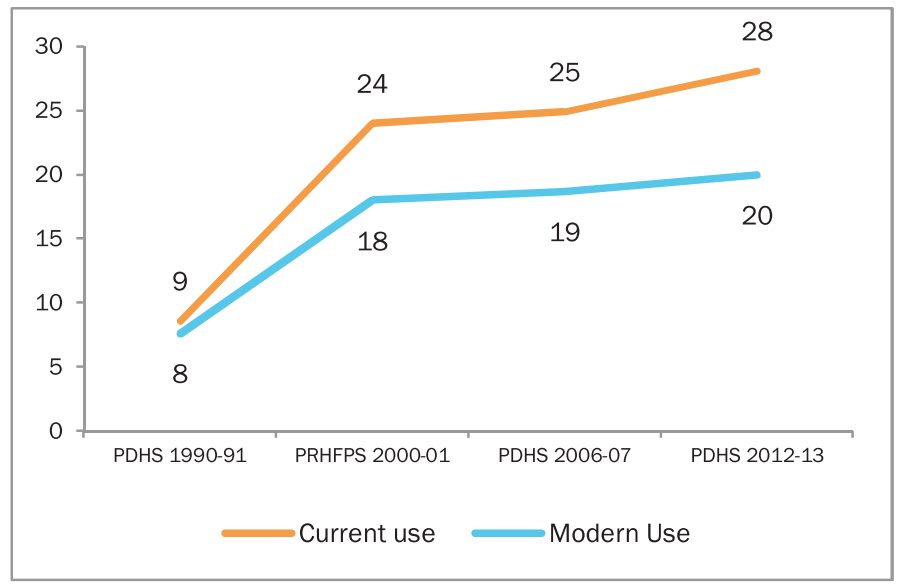

Figure 4: Contraceptive use in KP, 1991-2013

Urban-rural differences in contraceptive use remain significant the use of any method is 19 percentage points higher in urban areas than in rural areas. The use of traditional methods is higher in urban areas than in rural areas (14\% vs. $8 \%$ ), reflecting the greater use of withdrawal in urban KP.

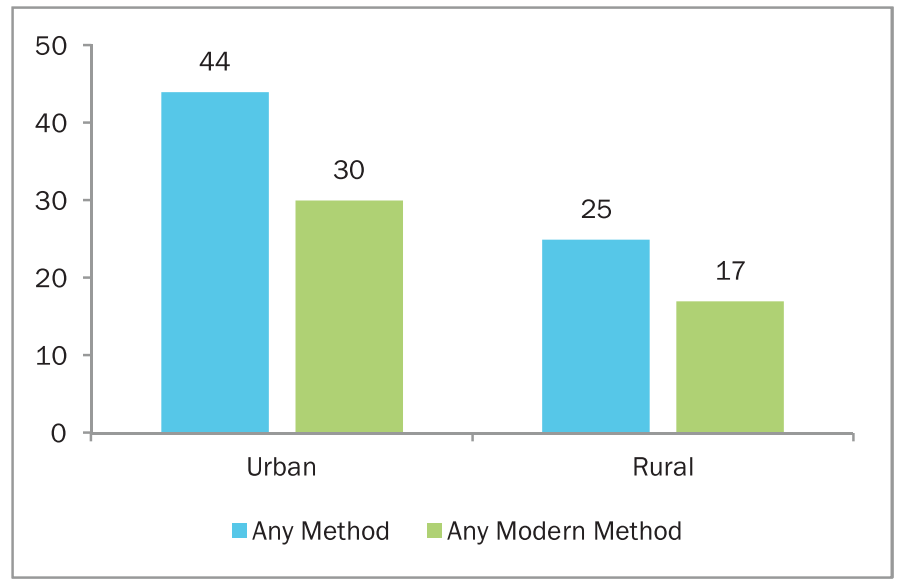

Figure 5: Contraceptive use by place of residence in $K P$

Source: PDHS 2012/13

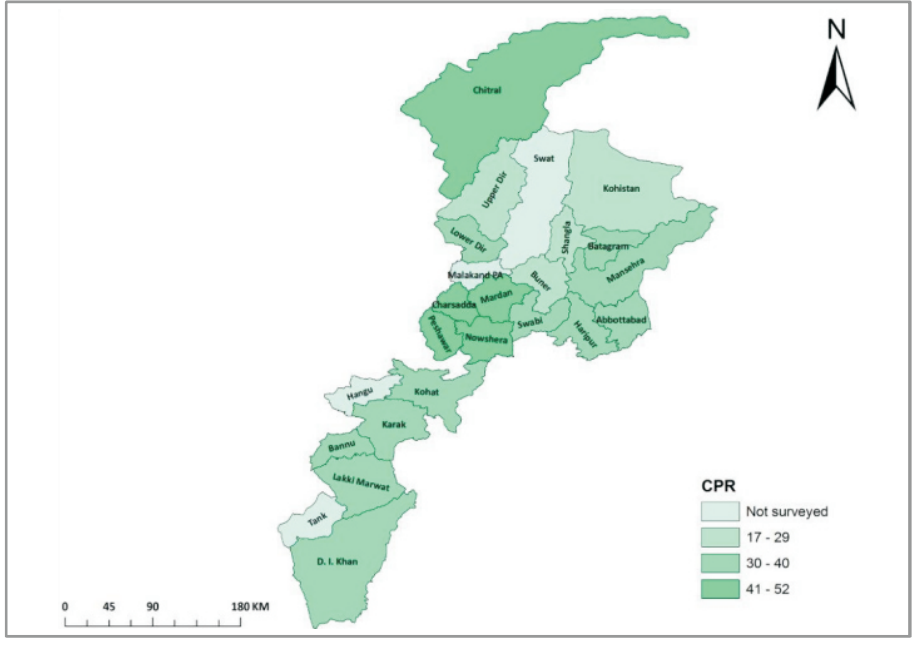

Figure 6: CPR by district in $K P$

Source: MICS 2008 for KP

There is considerable inter-district variation in the CPR (Figure 6). It is particularly low in the northern (except Chitral) and less developed districts of the province (e.g., $17 \%$ in Kohistan) compared to the central districts (e.g., 52\% in Mardan) (MICS 2008). Most districts in southern KP have moderate levels (30-34\%) of contraceptive use about 32\% in Dera Ismail Khan and 34\% in Bannu.

Fertility preferences show that most women would prefer to space or limit their next birth: 53\% want no more children and 19\% want to delay their next child by at least two years. Only $18 \%$ want another child soon within the next two years (Figure 7).

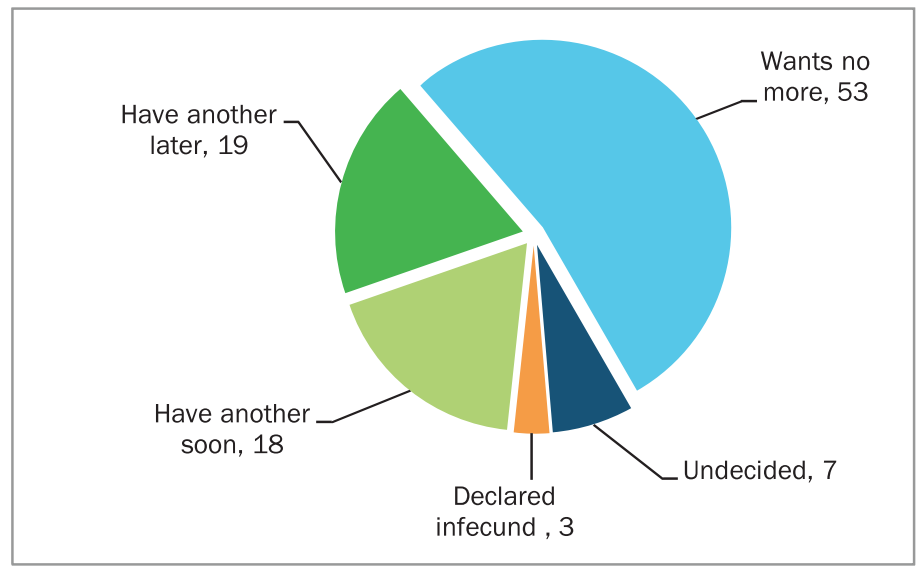

Figure 7: Fertility preferences of married women aged 15-49 years in KP Source: PDHS 2012/13

\section{$72 \%$ of women and $61 \%$ of men in KP prefer smaller and better-spaced families.}




\section{INFANT AND UNDER-FIVE MORTALITY RATES}

MDG 4 sets a target of reducing infant and under-five mortality by two thirds between 1990 and 2015. These rates have declined in KP from 1990 to 2012. The infant mortality rate (IMR) has decreased from 63 in 2006/07 to 58 per 1,000 live births in 2012/13 (Figure 8) and the under-five mortality rate has decreased from 75 to 70 between 2006 and 2012. KP has to bring down its infant and under-five mortality rates to 27 and 33, respectively, to achieve its MDG 4 targets.

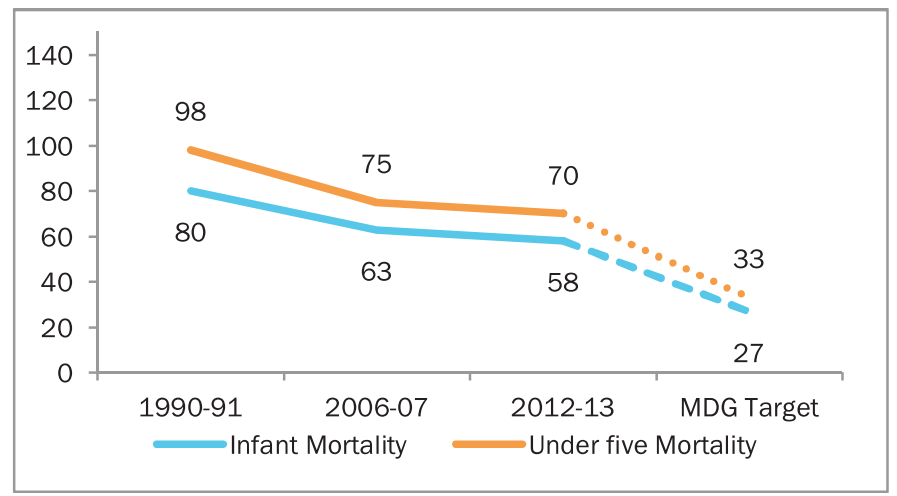

Figure 8: Infant and under-five mortality rates and MDG targets in $K P$ Source: PDHS

Averages tend to mask the variations in IMRs across socioeconomic groups and regions within the province. Maternal education has a considerable impact on the IMR - children with mothers who have had no schooling account for almost double the IMR of those whose mothers have studied up to or beyond secondary school (Figure 9). The differences by economic status, however, are less clear in KP.

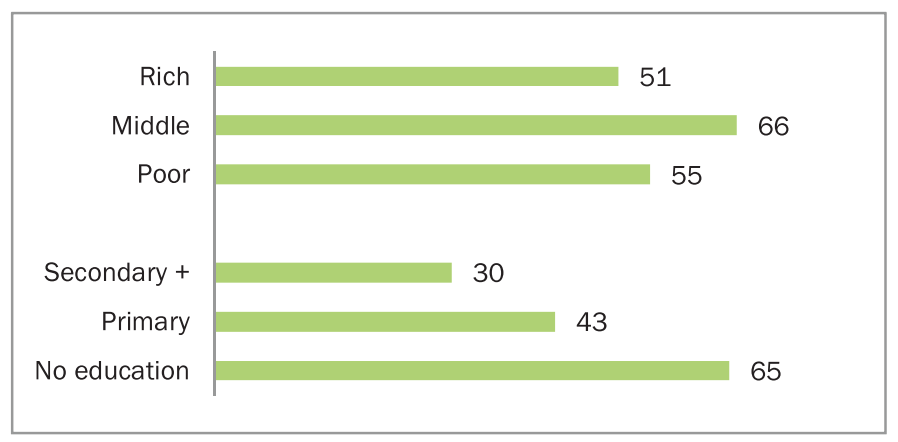

Figure 9: Socioeconomic differentials in IMR in $K P$

Source: PDHS 2012/13

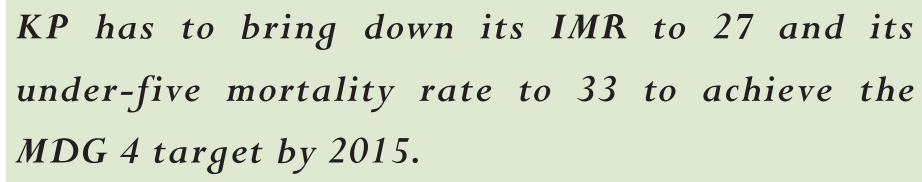

The IMR has declined significantly in both urban and rural areas from 78 to 52 per 1,000 live births in urban areas between 1990 and 2012, and from 81 to 58 per 1,000 live births in rural areas (Figure 10).

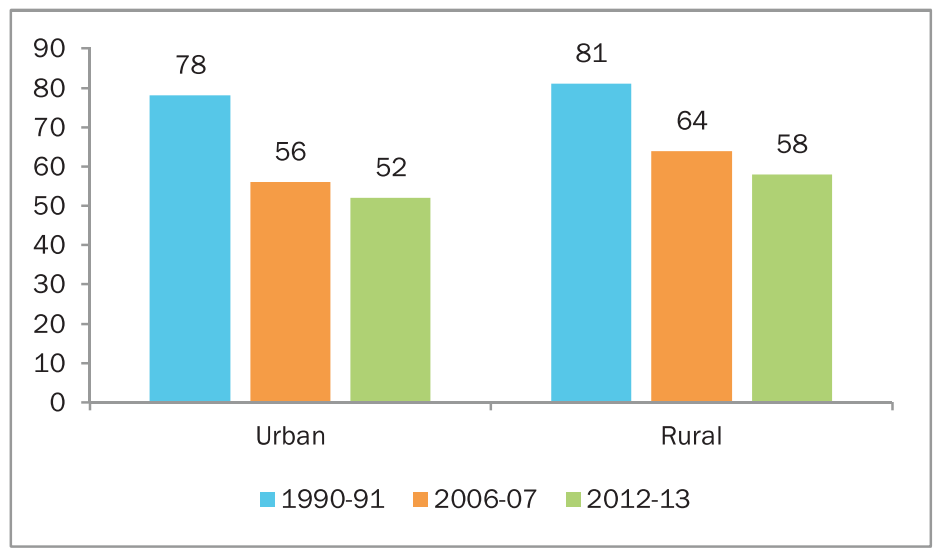

Figure 10: IMRs by place of residence

Source: $P D H S$

This calls for more attention, facilities, and care to be focused on the less developed regions of KP.

The children of the least educated mothers have higher IMRs. 


\section{THE MISSED OPPORTUNITY: BIRTH SPACING AND INFANT AND CHILD HEALTH}

KP's persistently high levels of neonatal and post-neonatal mortality are cause for alarm. Neonatal mortality decreased slightly from 48 to 41 per 1,000 live births between 1990 and 2006, and has stagnated in the last six years at 41 per 1,000 live births.

At the same time, post-neonatal mortality declined from 31 to 22 per 1,000 live births between 1990 and 2006. By 2012, it had fallen to 17 per 1,000 live births.

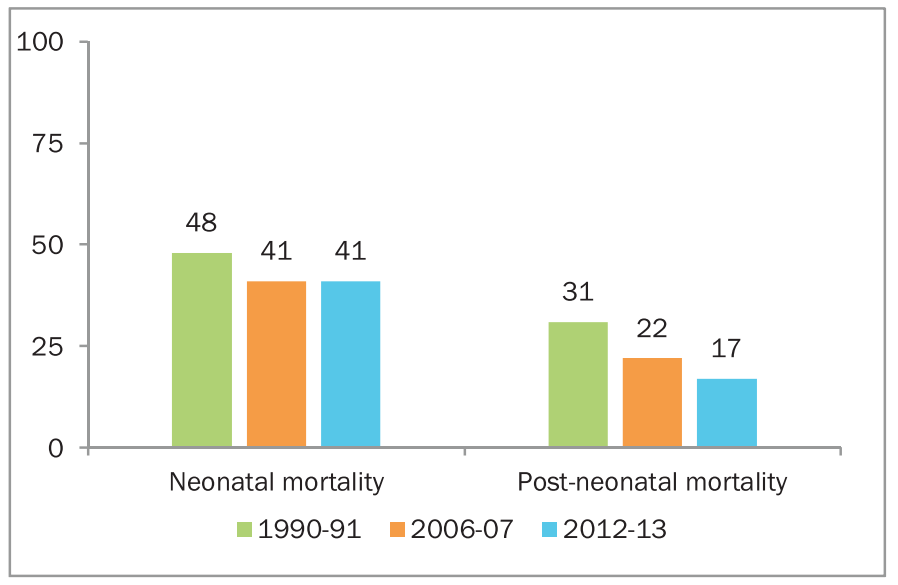

Figure 11: Neonatal and post-neonatal mortality rates in KP

Source: PDHS

The strong association between maternal health and infant survival, particularly for neonates, is the basis of the Healthy Spacing and Timing of Pregnancies initiative launched by the World Health Organization. A child's risk of dying is strongly correlated with certain fertility behaviours. The risk of death is much higher among children born to mothers who are too young (under 18 years) or too old (over 35 years) and among those born after a short birth interval (less than 24 months) or to mothers with high parity (3+ children).

About three fifths of the births in Pakistan are characterized as high-risk due to short intervals and high parity. Other interventions such as immunization and ORS are applied to prevent postneonatal deaths. However, the use of family planning to space births is an extremely effective but as yet untapped route to reducing infant and particularly neonatal mortality.
Improving access to and use of modern family planning methods would enable women to limit early or late childbearing and closely spaced births, thereby reducing the probability of infant and child mortality.

Birth intervals of less than two years account for the highest neonatal and post-neonatal mortality rates (Figure 12). There is a marked reduction in neonatal and post-neonatal mortality when the birth interval is two or more years. Neonatal mortality can be reduced to 21 per 1,000 live births with a birth interval of more than two years and to 13 per 1,000 with a birth interval of more than three years. Post-neonatal mortality would fall by two thirds with a birth interval of more than two years.

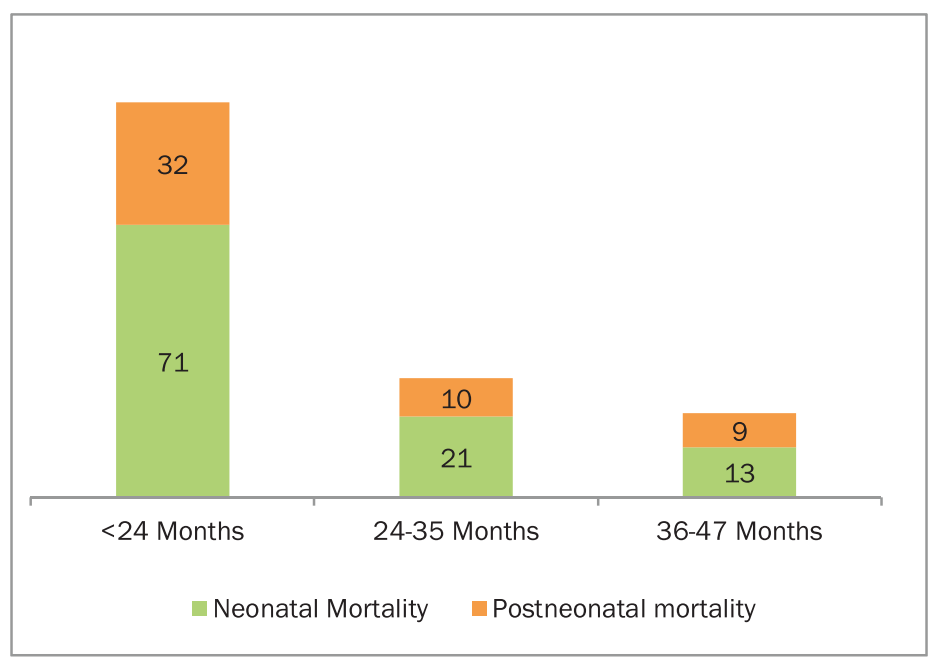

Figure 12: Neonatal and post-neonatal mortality in KP by birth interval Source: PDHS 2012/13

Women who practice family planning can avoid high-risk births and reduce their chances of having a baby who will die in the neonatal and infancy period.

\section{Longer birth intervals will help reduce neonatal mortality.}




\section{UNWANTED FERTILITY AND THE UNMET NEED FOR FAMILY PLANNING}

This brief presents a prescription for bringing about a significant decrease in the number of maternal deaths. It is well established internationally and in Pakistan that unintended pregnancies and unsafe abortions are leading causes of maternal deaths.

We also know that $72 \%$ of the women in KP want to prevent or delay their next pregnancy. Moreover, the recent PDHS for 2012/13 indicates that, despite some gains, there is still a large unmet need for family planning. About $26 \%$ of women have indicated an unmet need for contraception to space and limit their childbearing (Figure 13).

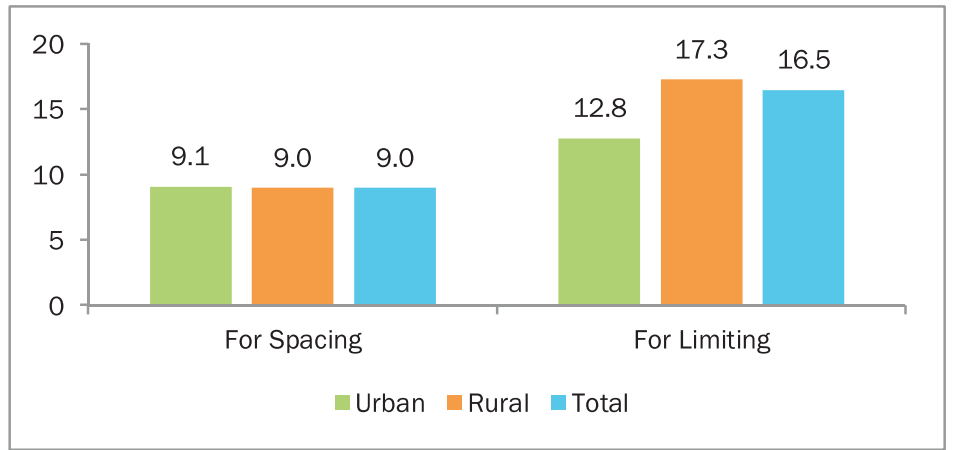

Figure 13: Unmet need for spacing and limiting by urban and rural residence in $K P$ Source: PDHS 2012/13

The unmet need for contraception to limit family size is higher in rural areas than in urban areas. This reflects greater room for raising the $\mathrm{CPR}$ in rural KP. If the demand for family planning were satisfied, the CPR would rise to $54 \%$ in $K P$.

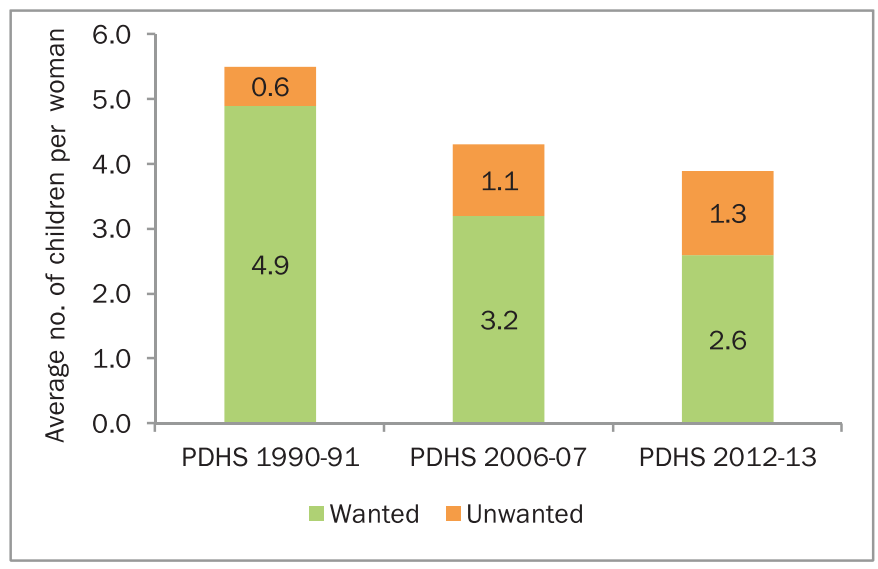

Figure 14: Average number of wanted and unwanted children per woman in $K P$

Source: PDHS

On average, a woman in KP has 3.9 children over her reproductive lifespan (Figure 14). If women could prevent the child that they did not want at all or wanted later, the fertility rate in KP would fall to 2.6 children per woman.

\section{POST-ABORTION COMPLICATIONS IN KP}

Unwanted pregnancies can also lead to post-abortion complications (PAC), which result primarily from induced abortions.

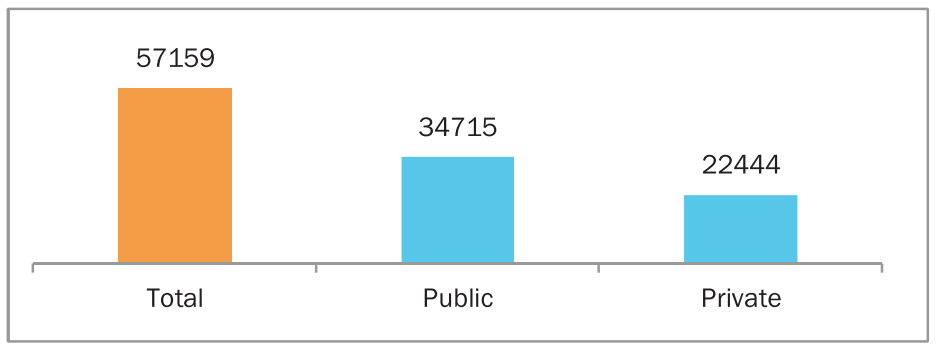

Figure 15: Number of PAC cases in KP

Source: Post-Abortion Care in Pakistan: A National Study, Population Council, 2013.
KP accounts for almost $8 \%$ of the annual PAC caseload out of a total of 696,000 cases estimated nationally. It has an estimated 57,159 PAC cases per year (Figure 15). Out of every 1,000 women of reproductive age (15-49), nine sought treatment for PAC in 2012 in KP. PAC cases are treated predominantly in the public sector in KP - about 61\% (Figure 15).

Investing resources in family planning would clearly help achieve MDGs 4 and 5 by preventing the nearly one third of total 1.3 million pregnancies in KP that are unintended. 


\section{POTENTIAL SCENARIOS FOR SAVING MOTHERS' AND CHILDREN'S LIVES}

\section{MATERNAL MORTALiTy}

There is untapped potential for increasing the CPR by accelerating the use of family planning to eliminate unmet need. Below, we present the potential benefits of increased family planning and skilled birth attendance (Figure 16) - the two major drivers of change in reducing maternal deaths.

This analysis includes three different scenarios to present the case for family planning and fertility decline as an effective way of reducing maternal deaths*.

Scenario 1: Increase the coverage of SBA to $80 \%$. This will lower the number of maternal deaths from 1,685 to 1,080, saving 605 maternal lives.

Scenario 2: Focus solely on increasing family planning and increase the CPR to $54 \%$ by eliminating the unmet need for family planning (26\%). This will reduce maternal deaths by $37 \%$ - from 1,685 to 1,063, saving 622 maternal lives.

Scenario 3: If the CPR is increased to $54 \%$ and SBA to $80 \%$, then the number of maternal deaths will drop to 679 - by more than a third of the current number of maternal deaths - saving 1,006 maternal lives.

Just increasing contraceptive prevalence to $54 \%$ will reduce the current number of maternal deaths by almost $37 \%$.

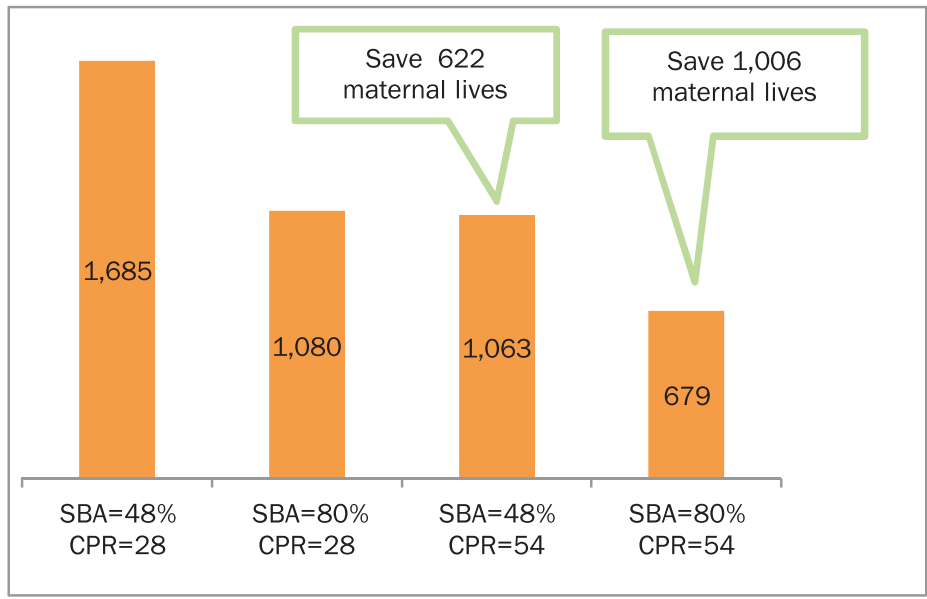

Figure 16: Impact of family planning on maternal deaths in KP Source: PDHS 2012/13 and simulations based on Maternal Mortality 2000: Estimates developed by WHO, UNICEF and UNFPA, WHO, and Liu et al. (2008).

\section{INFANT AND CHILD MORTALITY}

Using the established relationship between contraceptive use, high-risk fertility behaviour, and infant and child mortality, we have run simulations for two contraceptive-use scenarios that capture the effect of increased contraceptive use on infant and child mortality*.

Scenario 1: If contraceptive use increases to $41 \%$, the number of infant deaths will decrease from 47,444 to 39,109 , saving 8,335 infant lives. The number of child deaths (children aged 1-4) will fall from 9,816 to 5,837 , saving an additional 3,979 children's (aged 1-4 year) lives.

Scenario 2: By eliminating the entire unmet need for family planning in KP and increasing contraceptive use to $54 \%$, there would be 16,670 fewer infant deaths and 7,958 fewer child deaths (aged $1-4$ year).

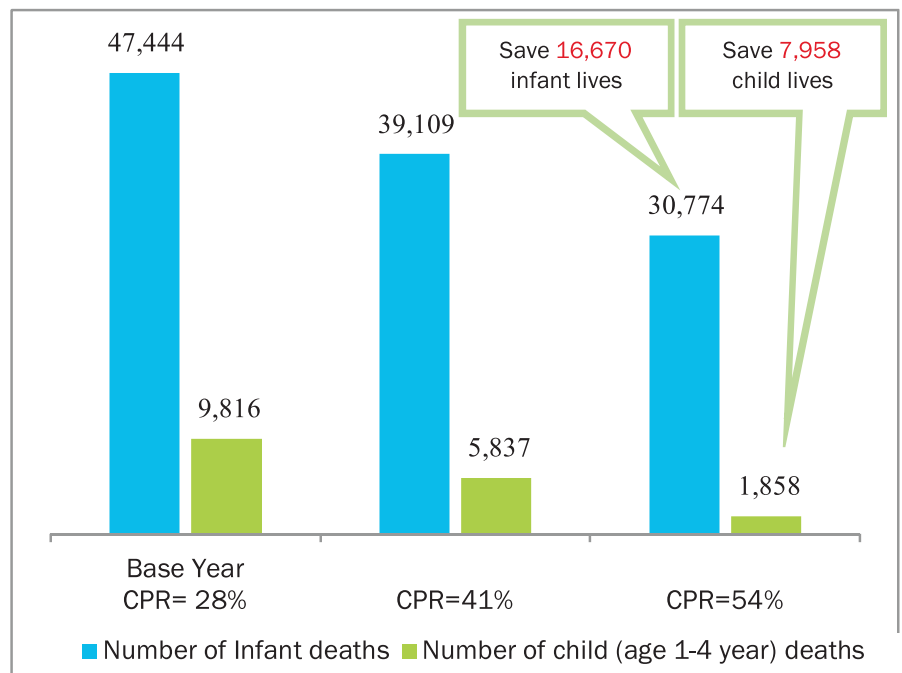

Figure 17: Impact of family planning on infant and child (age 1-4 yr) deaths Source: PDHS 2012/13 and simulation based on FAMPLAN model.

\section{6,670 infant and 8,000 child (ages 1 -4) deaths could be averted by eliminating the unmet need for family planning.}




\section{KP'S DEMOGRAPHIC PROSPECTS}

The population of KP has increased fivefold in the last 60 years since independence. However, the pace of growth accelerated during the 1980 s and 1990 s as mortality rates declined and fertility remained high. The population doubled from 8.4 million to 17.7 million between 1972 and 1998, and is close to 25 million today. KP's current annual population growth rate is around $2.3 \%$.

A rapidly growing population results in a struggle to ensure access to basic healthcare, education, and economic opportunities for an increasing number of people. KP's population of almost 25 million is already placing enormous stress on the province's infrastructure and resources.

\section{KP'S DEMOGRAPHICTRANSITION}

Figure 18 shows population pyramids for 1972, 2013, and 2050, which depict KP's transition in terms of age structure.

$\mathrm{KP}$ is currently passing through the middle phase of the demographic transition, although it still has a large youth population: $70 \%$ of the province's population was under the age of 30 in 2013. If fertility rates continue to decline at a moderate pace, by 2050 the proportion of the population under 30 years of age will have decreased to $47 \%$. Falling dependency ratios resulting from a rising working-age population and declining numbers of children and the elderly offer the opportunity of a demographic dividend in KP.

\section{FERTILITY DECLINE: SLOW AND UNEVEN}

Although the population continues to grow, fertility rates have declined significantly throughout the province since the 1970 s (Figure 19). Fertility dropped from 6.2 children per woman in the 1970 s to 5.5 in 1991 . The total fertility rate (TFR) in 2012 was 3.9 children per woman.

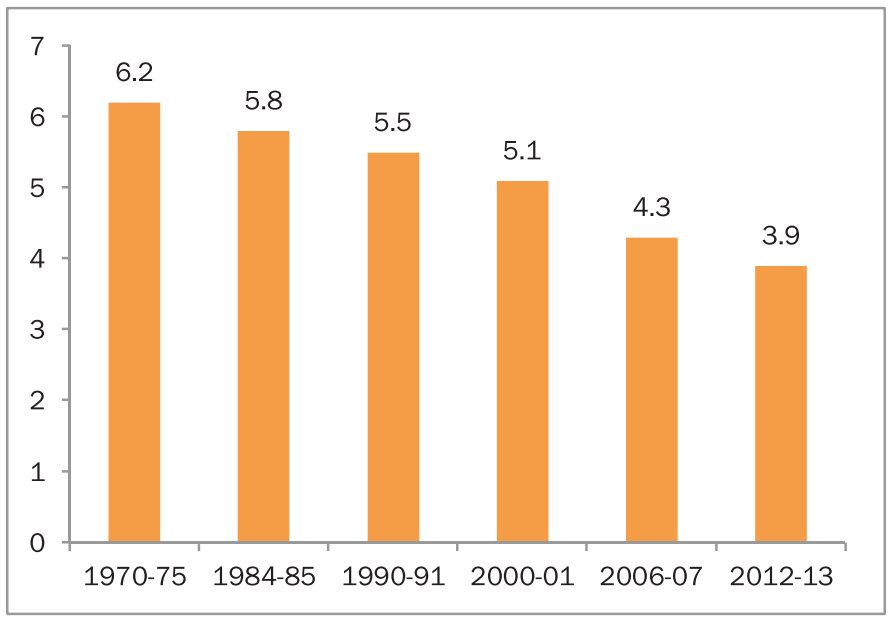

Figure 19: Total fertility rates in KP, 1974-2013
1972

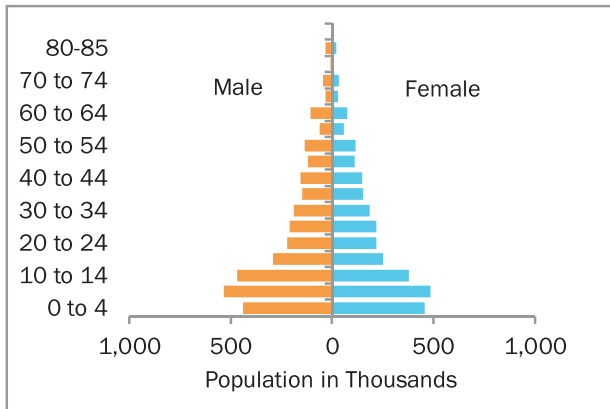

Figure 18: Stages of the demographic transition in KP Source: Population Council estimates
2013

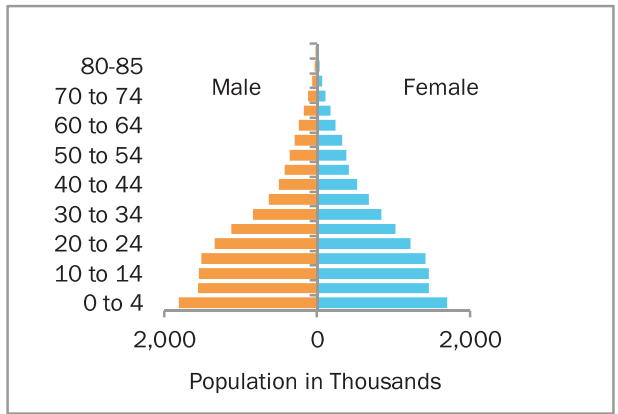

2050

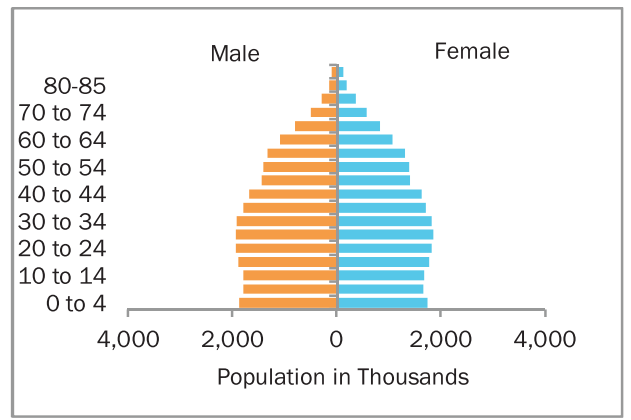

$\mathrm{KP}$ has the chance to benefit from a fertility decline that could result in both improved maternal and child health and economic development through the demographic dividend. 


\section{Briefing Paper - Khyber Pakhtunkhwa}

Despite overall gains in fertility reduction, the change has not been uniform across the province. There are significant differences in fertility rates by place of residence and socioeconomic status. Women in rural KP continue to have almost one child more than their urban counterparts, while poor families have approximately 1.4 children more than rich families (Figure 20).

Fertility rates are also lower for women with higher levels of education: the TFR is 4.3 for those with no education, 4.1 for those with primary schooling, 3.4 for those with secondary education, and 2.9 for those with tertiary education.

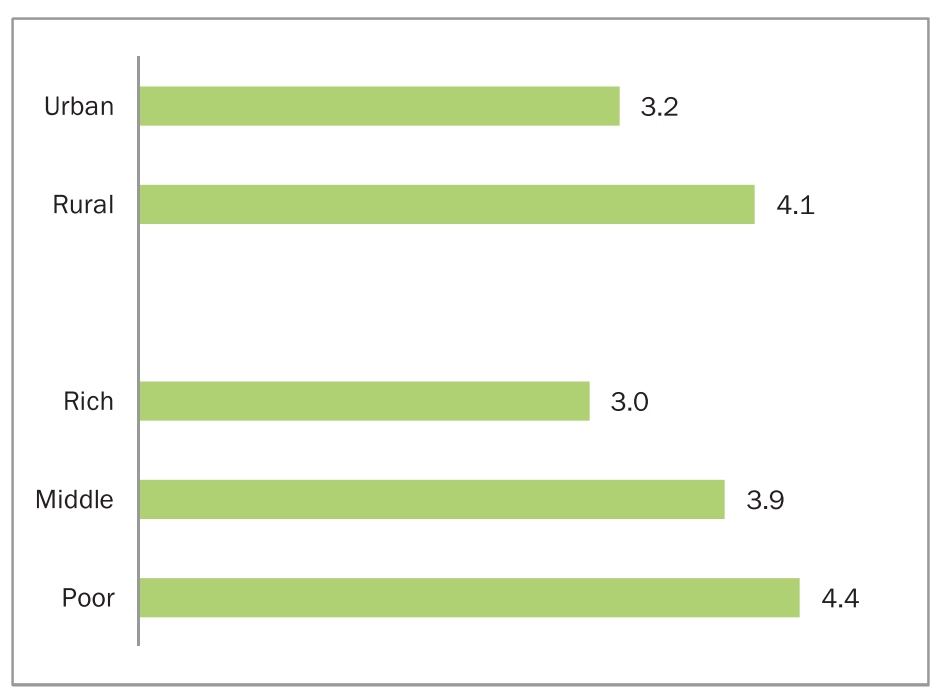

Figure 20: Fertility rates by place of residence and socioeconomic status in $K P$ Source: PDHS 2012/13
KP's population will continue to grow over the next few decades, largely due to continuing high levels of fertility and the population momentum built into the growth rate, given the province's youth population. Future growth will be driven by three main demographic factors:

- $\quad$ The persistently high levels of fertility, particularly in rural KP

- $\quad$ A very young age structure due to high fertility in the past

- The large number of women who are entering childbearing age.

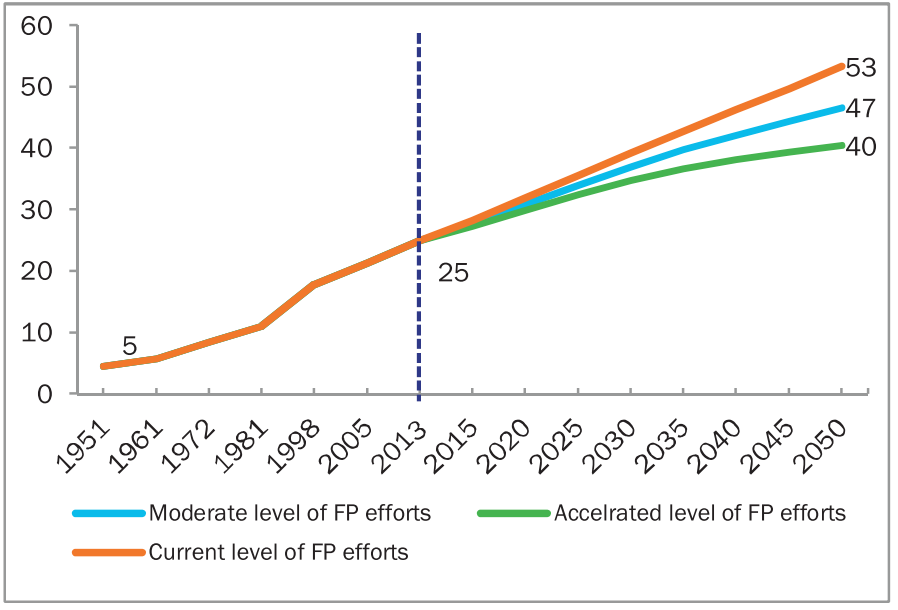

Figure 21: Population projections for KP, 1951-2050

Source: Population Council

Future fertility levels will determine whether the population of KP will rise to 40 million or 53 million by 2050 (Figure 21). The decision to invest in a rapid fertility decline through a strong family planning program could make the difference of 13 million more people in KP by 2050. 


\section{BRINGING IT ALL TOGETHER: THE BENEFITS OF MEETING THE UNMET NEED FOR FAMILY PLANNING AND ACCELERATING THE FERTILITY DECLINE}

Reducing the unmet need for family planning offers the opportunity to lower infant, child, and maternal mortality through the provision of good-quality family planning services in KP. Expanding family planning services and increasing contraceptive use will have a direct impact on the birth rate and on maternal mortality.

Clearly, investing resources in family planning would help achieve MDGs 4 and 5 by preventing the nearly one third of 1.3 million pregnancies in KP that are unintended.

The decrease in the number of unwanted pregnancies will reduce recourse to unsafe abortions as well as the number of post-abortion care clients. It will also reduce the number of deliveries significantly, allowing the KP government to better utilize its already overburdened resources and facilities to improve the quality of maternal care.

\section{The Key to EXPANDing ACCeSs to FAmily PlanNing Service Delivery}

Access to family planning services will increase substantially if the entire public health system delivers these services. In particular, lady health workers (LHWs) are needed to facilitate the outreach of family planning services. Figure 22 shows how access to family planning services is limited if they are provided solely by the Population Welfare Department through family welfare centres (FWCs) in Charsadda. The GIS maps are based on a census of reproductive health facilities and show how family planning services can be enhanced dramatically for this district if Department of Health (DOH) static outlets and LHWs are effectively involved.
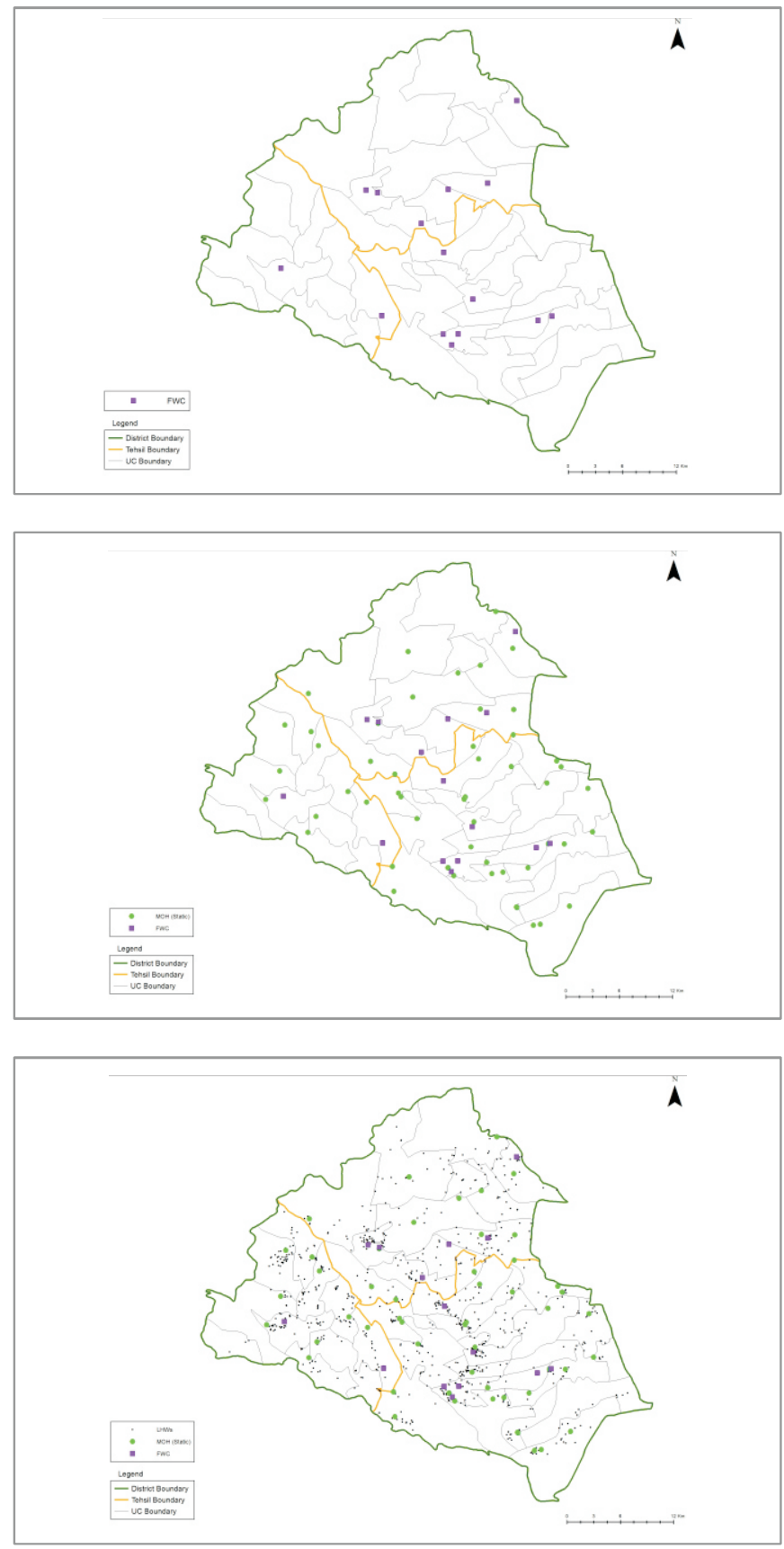

Figure 22: Map of Charsadda district: a) Just FWCs, b) FWCs with $M O H$ static clinics, and c) FWCS, static clinics, and LHWs.

Source: FALAH GIS Mapping Survey, 2008. 


\section{CONCLUSIONS}

This briefing paper combines a wide range of data sources, including several rounds of the PDHS 2012/13, and MICS 2008, to make the case for prioritizing family planning to meet MDGs 4 and 5 .

Although fertility rates have declined in KP, wide differentials persist. Progress in the stages of the fertility transition across districts is uneven, and greater efforts are required to establish parity in the fertility decline, especially in rural KP.

Infant and child mortality remain high. Neonatal mortality rates in KP have remained stagnant over the last 20 years. Among the major factors behind the persistently high infant and neonatal mortality rate are high fertility and short birth spacing. It is now well established that longer intervals between births decrease neonatal and infant mortality. Family planning offers a route to lowering both neonatal and infant mortality.

While wanted fertility has declined in KP, unwanted fertility has increased. The unmet need for family planning has also declined slightly, but remains substantial especially in rural KP.

The data establishes a strong connection between family planning and maternal mortality. Given the uneven geographical patterns across KP, policymakers will have to focus on particularly vulnerable regions and segments of the population to improve the province's indicators. There is an opportunity to bring the health and population welfare sectors together to expand access to family planning services. Addressing the unmet family planning need in KP will not only lead to marked reductions in both maternal and infant mortality, but its benefits will also spur other important outcomes in education, employment, and economic opportunities. KP is well positioned to benefit from a demographic dividend, but accelerating the fertility decline is a necessary precondition.

\section{SOME RECOMMENDATIONS TO ACCELERATE FAMILY PLANNING EFFORTS}

$>$ Increase provincial political support and resource allocation for family planning efforts.

$>$ Promote family planning as a health intervention.

$>$ Include birth spacing services as part of the health policy.

$>$ Ensure the availability of contraceptive supplies by strengthening procurement and logistics systems for all public health and private service outlets.

$>$ Improve the technical and communication skills of service providers through client-centered family planning training for better service quality.

$>$ Utilize the Population Welfare Department's training facilities to train health providers.

$>$ Focus on vulnerable regions and segments of the population.

$>$ Increase access through public-private partnerships and by contracting out mechanisms already being promoted by the provincial government to improve service delivery.

* A more detailed report titled "Prioritizing Family Planning for Achieving Provincial Maternal Child Health and Development Goals" elaborates on the data and methods presented in this briefing paper.

\section{POPULATION -1 COUNCIL}

Ideas. Evidence. Impact. House 7, Street 62, F-6/3, Islamabad Phone: 051-8445566 Fax: 051-2821401 Info.pakistan@popcouncil.org www.popcouncil.org

\section{Evidence}

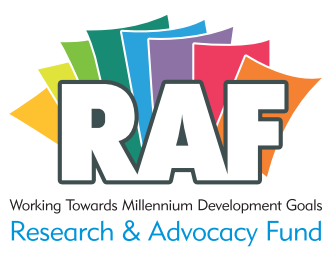

Research \& Advocacy Fund 